Journal of Physical Oceanography, Vol. 22, No. 1, pp. 93-104 (1992)

10 1175/1520-0485(1992)022<0093:ROWMFI $>2.0 . C O ; 2$

\title{
Rates of Water Mass Formation in the North Atlantic Ocean
}

\author{
KEVIN SPEER \\ Institut für Meereskunde, Kiel, Germany
}

ELI TZIPERMAN

The Weizmann Institute of Science, Rehovot, Israel

(Manuscript received 10 December 1990, in final form 28 May 1991)

\section{ABSTRACT}

\begin{abstract}
North Atlantic air-sea heat and freshwater flux data from several sources are used to estimate the conversion rate of water from one density to another throughout the range of sea surface density. This cross-isopycnal mass flux varies greatly over the ocean, with a maximum of $32.2 \times 10^{6} \mathrm{~m}^{3} \mathrm{~s}^{-1}$ at $\sigma=26.1 \mathrm{~kg} \mathrm{~m}^{-3}$ (toward greater densities) and a minimum of $-7.6 \times 10^{6} \mathrm{~m}^{3} \mathrm{~s}^{-1}$ (toward lesser densities) at $\sigma=23.0 \mathrm{~kg} \mathrm{~m} \mathrm{~m}^{-3}$. The air-sea fluxes force water to accumulate in three density bands: one at the lowest sea surface densities generated by heating; one centered near the density of subtropical mode water; and one spanning subpolar mode water densities. The transfer of water to the highest and lowest densities is balanced by mixing, which returns water to the middle density range, and also by boundary sources or sinks. Integrating the cross-isopycnal flux over all densities gives an annual average sinking of about $9 \times 10^{6} \mathrm{~m}^{3} \mathrm{~s}^{-1}$, which presumably escapes across the equator and must be balanced by a similar inflow. Comparison with estimates from tracer studies suggests that the renewal of tracer characteristics at a given density may occur without the existence of an annual average mass source at that density, because along- and cross-isopycnal mixing can renew a tracer without supplying mass.
\end{abstract}

\section{Introduction}

Air-sea fluxes of heat and freshwater at the ocean's surface change temperature and salinity characteristics and convert water from one density to another. If the rate of conversion varies, then, in general, water tends to be removed from some density ranges and to accumulate at others. For example, if the conversion rate diminishes over a certain surface density range, water tends to accumulate as more water enters this density range than leaves it. This simple idea (Walin 1982) leads to the possibility of quantitative estimates of the formation rate of various water masses, using only airsea fluxes and sea surface density data. We report here such estimates, made using recently compiled climatological datasets for the North Atlantic.

The need for quantitative estimates of water mass formation rates is clear from their relation to the climatic state of the ocean. For example, the North Atlantic Ocean has a number of layers of distinct water mass characteristics. The most important of these in a volumetric sense are called mode waters, and one would like to understand the nature of their creation and evolution. Mode water is thought to result from convection during late winter periods of strong buoy-

Corresponding author address: Dr. Kevin Speer, Institut für Meereskunde, Düsternbrooker Weg 20, D-2300 Kiel, Germany. ancy loss, though how much, if any, is formed each winter is not well known. As Warren (1972) pointed out with respect to subtropical mode water, the variety of wintertime conditions appears to be so great that if substantial formation occurred each year the result would seem more likely to erase the mode water characteristics rather than continue them. Using a model for the heat content in a column of water above the main thermocline, he showed that (after an initial formation period of about 8 years) the main effect of the expected air-sea heat flux near $35^{\circ} \mathrm{N}, 60^{\circ} \mathrm{W}$ was restricted to the shallow, seasonal thermocline.

On the other hand, convection at more northerly latitudes reaches below the seasonal thermocline and does appear to erase old characteristics in underlying homogeneous layers, eventually leading to the formation of subpolar mode water and Labrador Sea Water (McCartney and Talley 1982). This water was tracked around the subpolar gyre and it was subsequently shown that the modification to temperature that it endures is consistent with the loss of heat to the atmosphere thought to be representative of the region (McCartney and Talley 1984). A net advection of heat into the region was required to balance this loss, which was ascribed to a northward flow of $14.1 \times 10^{6} \mathrm{~m}^{3} \mathrm{~s}^{-1}$ at $11^{\circ} \mathrm{C}$. Of this, $11.1 \times 10^{6} \mathrm{~m}^{3} \mathrm{~s}^{-1}$ were converted to water of greater density, which returns south at depth, while the remainder returns south as a cold, but less dense surface current (the Labrador Current). 
At warmer upper-thermocline densities, the best estimates of the overall amount of water formed are thought to come from measurements of radioactive tracers of ocean circulation (Sarmiento 1983). Using tritium measurements he inferred residence times in a number of layers at intervals of $0.1 \times 10 \mathrm{~kg} \mathrm{~m}^{-3}$ in potential density anomaly referenced to the surface $\left(\sigma_{\theta}\right.$; note that $\sigma_{\theta}=\sigma_{t}$ for surface data, henceforth units and subscript are dropped). The potential density anomaly ranged from 26.2 to 27.4. Over this range he calculated that about $40 \times 10^{6} \mathrm{~m}^{3} \mathrm{~s}^{-1}$ moves from the mixed layer to the interior, according to the residence times and interior volume estimates. ${ }^{1}$

Tracer age estimates are influenced by both tracer advection and diffusion (Sarmiento 1983), so not all of this exchange need be accomplished by the actual movement of water between boxes. If this exchange represents a net loss of mass by the surface layer at densities greater than 26.2 then it presumably is balanced by the transformation of $40 \times 10^{6} \mathrm{~m}^{3} \mathrm{~s}^{-1}$ across the 26.2 isopycnal. The question of the compatibility of such a transformation with air-sea fluxes was not addressed.

In this study we calculate the transformation of water that is the result of air-sea fluxes over the surface density range of the North Atlantic Ocean resolved by our dataset. In addition, the amount of water produced or formed at each density may be estimated. We use only data pertaining to the sea surface: heat and freshwater fluxes, temperature, and salinity. Thus, unlike other known studies, the method we use is not a box model, in the sense that no water mass volumes or volumeaveraged quantities need be specified. Such quantities usually depend on unknown mixing processes going on within the box for physical meaning. It is remarkable that our results show a trend similar to the previous ones despite the very different method used to compute them. At $\sigma=26.2$ we get a net transformation of 29.2 $\times 10^{6} \mathrm{~m}^{3} \mathrm{~s}^{-1}$ and at $\sigma=27$ the transformation is 16.8 $\times 10^{6} \mathrm{~m}^{3} \mathrm{~s}^{-1}$. The error in the various results is sufficient to explain the difference, but the point here is not so much the values themselves as the implication that roughly half of the poleward cross-isopycnal transport generated by air-sea fluxes goes into the upper thermocline, while the other half continues into the subpolar gyre to be converted into dense deep water.

The basis for our calculation is due to Walin (1982), who showed that the amount of surface water spreading from warm midlatitudes toward cooler, higher latitudes

\footnotetext{
${ }^{1}$ Considering various sources of error, Sarmiento (1983) suggested that a more realistic estimate might be $25 \%-38 \%$ lower; however, Doney and Jenkins (1988) argued that his age estimates ought to be reduced, thus, raising the estimated transfer. Substituting their new age values in the density range $26.2-26.9$ gives a total exchange which is greater by $10 \%-30 \%$. Given the uncertainties we use Sarmiento's original results for comparison.
}

might be estimated from surface heat flux and surface temperature alone. In his conception this "poleward drift" is forced by gravity while its strength is controlled by air-sea heat flux, since the water must lose heat to cross isotherms and reach higher latitudes. It is not possible to say from this calculation alone exactly where this drift is located, though in regions of cooling it is presumably associated with convection. In low-latitude regions of heating the direction of transformation is reversed, and a strong cross-isothermal mixing was inferred to cool the water and thus eventually return it to higher latitudes. The location of this transfer is also unknown, but the tendency of warm water to spread over cold water suggests that it may be much less localized than convection. The relative importance of the various energy sources, such as heating, flow, and wind stress, to the instabilities that do the mixing is unclear.

Andersson et al. (1982) arrived at a preliminary estimate of $10 \times 10^{6} \mathrm{~m}^{3} \mathrm{~s}^{-1}$ for the poleward drift in the North Atlantic, using heat flux data provided to them by Bunker. Tziperman (1986) showed that by considering the variation of heat flux with temperature in more detail the method may be extended to determine the amount of water formed at all temperatures, or more generally at all densities using the air-sea density flux. Tziperman and Speer applied this method to estimate transformation in the Mediterranean Sea and found a thermohaline circulation several times stronger than that implied by the flow through the Strait of Gibraltar.

\section{Method}

As outlined above, by calculating the air-sea density flux that surface water of a given density experiences on average, rather than examining this flux as a function of time and location, it is possible to determine the amount of water formed at that density. Only a summary of the derivation of the expression for water mass transformation and formation are given here (for details see Tziperman 1986).

The density flux at the sea surface is

$$
f=\frac{-\alpha H}{C_{p}}+\rho(0, T) \beta \frac{(E-P) S}{1-S}
$$

with the thermal expansion and saline contraction coefficients given by

$$
\alpha=-\frac{\partial \rho}{\rho \partial T}, \quad \beta=\frac{\partial \rho}{\rho \partial S} .
$$

In these expressions, $\rho(S, T)$ is density, $T$ and $S$ are sea surface temperature (SST) and salinity (SSS), $H$ is the heat flux into the ocean, $E$ and $P$ are evaporation and precipitation, and $C_{p}$ is the specific heat. All the terms are functions of position and time. The total 
density flux for one year as a function of sea surface density $(\mathrm{SS} \sigma)$ is

$$
F(\rho)=\int_{\text {year }} d t \iint_{\text {area }} d A F \delta\left(\rho-\rho^{\prime}\right),
$$

where the delta function samples the density flux at the surface density $\rho$. The transformation $F(\rho)$ is the analogue of the derivative with respect to temperature of the thermal forcing function $Q(T)$ discussed by Walin (1982). Tziperman (1986) showed that $F(\rho)$ is equal to the total mass flux across the isopycnal $\rho$ during one year. It represents a mass flux because water has a certain specific heat, which governs the amount of mass that changes temperature for a given energy input. Similarly, the amount of water that changes from one salinity to another as a result of evaporation and precipitation depends on the salinity of the water.

In the ocean two types of cross-isopycnal mass transfer occur, indistinguishable in our calculation. In a steady state with the location of isopycnals fixed, the flux consists of an actual movement of water to a new position across isopycnals, with density advection balancing the gain or loss to the atmosphere. In the unsteady case, water may simply change density according to the air-sea flux without moving-a purely local response. Just how the water moves in response to the flux is ignored here (see Warren 1972, for a discussion of one- and two-dimensional models of subtropical mode water response to air-sea fluxes).

The water mass that accumulates over the year between any two isopycnals $\rho$ and $\rho+d \rho$ is

$$
M(\rho) d \rho=-[F(\rho+d \rho)-F(\rho)],
$$

so that the formation per unit density $M(\rho)$ is $M$ $=-d F / d \rho$. Note that we distinguish between the transformation of water $F$ and the formation $M$. (This terminology is convenient but admittedly imperfect because water does exist at densities at which the formation is zero or negative; nevertheless, the usage is standard.)

The other sources of mass to a given density range are mixing $M_{M}$ and boundary sources $M_{B}$, if the domain is not closed by land. Examples of boundary sources include the Mediterranean outflow, the Denmark Strait overflow, and cross-equatorial flow. Potential sources of heat and salt via along-isopycnal mixing at open boundaries are ignored. Taking all the sources into account the total mass balance for water of a given density may be written as $M(\rho)+M_{M}(\rho)$ $+M_{B}(\rho)=0$.

\section{Data}

The air-sea heat flux data of Budyko (1956) and Bunker (1976) and the revised Bunker values com- puted by Isemer and Hasse (1987) were used and compared. These data have been interpolated to a $1^{\circ} \times 1^{\circ}$ grid with monthly time resolution by Isemer and Hasse (1987). Dorman provided rainfall on $2^{\circ} \times 5^{\circ}$ boxes, which we interpolated to a $1^{\circ} \times 1^{\circ}$ grid. Sea surface salinity is not part of the standard meteorological data, and we used Levitus' (1982) values, interpolated from seasonal to monthly resolution. Isemer and Hasse's (1987) dataset extends as far as $65^{\circ} \mathrm{N}$. Some calculations were made for regions farther north using the original Bunker data.

The use of fluxes calculated from empirical formulas and climatological data in the calculation introduces three different sources of error. First of all is the problem of the parameterization used to derive air-sea fluxes from the basic meteorological variables. This problem is well known (e.g., see Isemer et al. 1989), but it is still difficult to attach an overall error to a result because uncertainties in the parameterization have different consequences depending on the time and region. Based on Isemer et al.'s (1989) rms heat flux error of $22 \mathrm{~W} \mathrm{~m}^{-2}$ for the annual average, a rough estimate of the overall error in the calculation of $F$ can be made by adding noise of this strength to the heat flux and redoing the calculation. The resulting rms error in the annual average is $0.3 \times 10^{6} \mathrm{~m}^{3} \mathrm{~s}^{-1}$. This is an error of only a few percent over most of the surface density range. A larger error resulting from unknown systematic errors in the basic meteorological variables and the parameterization is likely. The second source of error is simply missing water-mass formation events. The density of ship and other observations comprising the basic meteorological dataset may be quite low in regions and times of heavy weather and away from commercial ship tracks. Finally, the averaging required to assemble a climatology necessarily reduces the influence of small-scale, intermittent phenomena, such as cold fronts thought to characterize some water mass formation processes. This last error was discussed by Tziperman and Speer, who concluded that the key quantity controlling the magnitude of the error was surface density rather than the air-sea heat flux. The reason for this was the heat flux fluctuations at an average $\mathrm{SS} \sigma$ tend to cancel, while the distribution of the average flux over a fluctuating sea surface density tends, on the contrary, to generate water of a new density. Presumably the error in SS $\sigma$ is substantially less than that in the derived heat flux, adding confidence to the calculation.

Maps of seasonal and annual average density flux over the North Atlantic have been presented by Schmitt et al. (1989) and it is helpful to refer to these to see its spatial distribution. They also discuss some of the errors in the different datasets.

Since our dataset is not continuous, the calculation is done in practice by summing over the partitions 


$$
\begin{aligned}
F(\rho)=\frac{1}{\Delta \rho} & \sum_{n=1}^{12} \Delta t \sum_{i, j} \Delta A_{i, j} \\
& \times\left[\frac{-\alpha H_{i, j}^{n}}{C_{p}}+\rho \beta \frac{(E-P)_{i, j}^{n} S}{1-S}\right] \Pi\left(\rho-\rho^{\prime}\right),
\end{aligned}
$$

where the terms are now evaluated by grid point $i, j$ and for each month $n$. The delta function has become a boxcar of width $\Delta \rho$ in this discrete form. This procedure is very similar to that used by Andersson et al. (1982) for estimating their function $Q$.

The allowed temperature range was $-2.88^{\circ}$ to $30^{\circ} \mathrm{C}$. The salinity range was 0 to 37.5 psu. Very low salinities in some high latitude marginal regions, such as Baffin Bay, and near large river outflow, such as the Amazon, created very low densities. The lower cutoff was fixed at $\sigma=20$. No upper cutoff was chosen, and $\sigma=28$ was high enough to include all of the remaining data. Approximately $2 \%$ of the data was lost each month because of this selection and missing rainfall values.

The density bin width was chosen to be $\Delta \rho=0.1$ $\times 10 \mathrm{~kg} \mathrm{~m}^{-3}$, or $\Delta \sigma=0.1$. A much finer width is not sensible given the resolution of the data and the distance between isopycnals at the surface, whose density differs by this bin width. Some effects of varying $\Delta \rho$ are discussed later to give an idea of the precision of the calculation.

\section{Results}

\section{a. Transformation}

The three heat flux datasets lead to mass flux estimates $F(\rho)$, which are very different at low density but similar at high density (Fig. 1). Positive values imply a transformation to greater densities, and the Budyko dataset shows the greatest of all three. In fact, there is scarcely any production $(-d F / d \rho)$ at all at the lowest

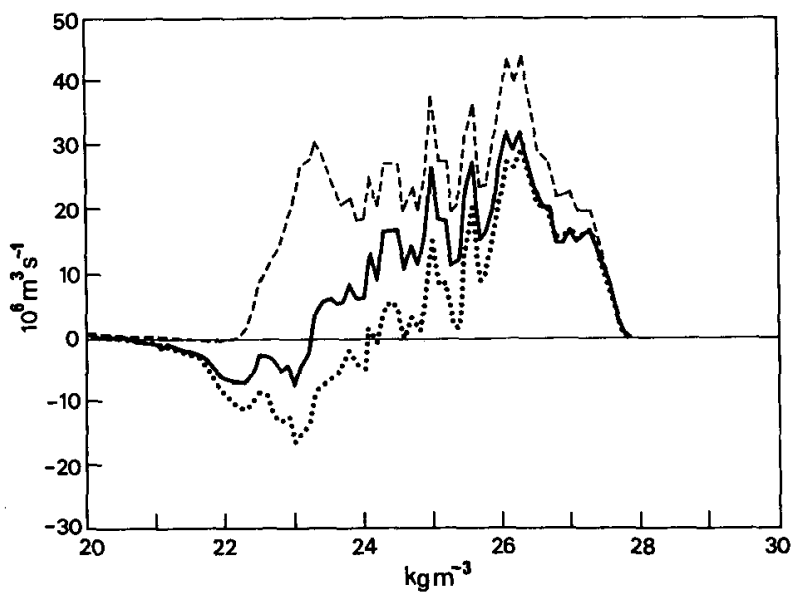

FIG. 1. Cross-isopycnal mass flux or transformation as a function of sea surface density for three climatological datasets: Budyko (dashed), Isemer and Hasse (solid), and Bunker (dotted).

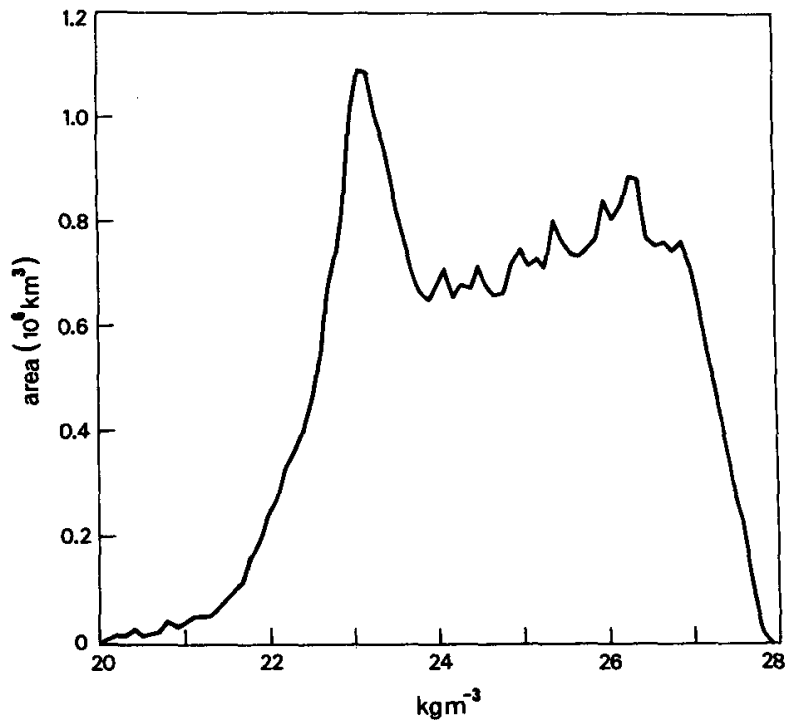

FIG. 2. Annual average area of each density class $\left(\Delta \sigma=0.1 \mathrm{~kg} \mathrm{~m}^{-3}\right)$.

densities for the Budyko fluxes, while the other datasets show a negative densification (heating of warm water). This situation is consistent with the known underestimate of the shortwave component of heat flux by Budyko's formula (Isemer et al. 1989). The Bunker (1976) and revised Bunker data of Isemer and Hasse (1987) differ by less than $10 \%$ in the annual mean at densities greater than 26 , but below this the Bunker curve is shifted in the direction of a weaker cooling (or stronger heating). The Isemer and Hasse revision shows less heating in warm, generally low-latitude regions. At either end of the curve, the transformation falls off to zero as the surface area of the density bin becomes tiny, that is, very little water of extreme density is found at the surface (Fig. 2). Note that although the annual average transformation is similar in the Bunker and revised Bunker datasets at high density, the seasonal variation of the various components of heat flux is not the same. In the following we restrict our discussion to the revised Bunker fluxes since these take into account recent turbulent transport coefficient measurements and corrected wind fields.

The major peak near $\sigma=26$ shows that about 30 $\times 10^{6} \mathrm{~m}^{3} \mathrm{~s}^{-1}$ are transformed to greater densities during the year. This is the amplitude of convection in the North Atlantic, in the sense that it is the maximum cross-isopycnal transport that occurs as a result of airsea interaction. Of the water supplied to densities greater than 26 , roughly half goes to the density range 26 to 27 , and the other half to the range 27 to 28 .

At the warm water end of the transformation curve, nearly $8 \times 10^{6} \mathrm{~m}^{3} \mathrm{~s}^{-1}$ goes to densities lower than 22 or 23 . The curve is ragged at lower densities and the peak does not occur at a well-defined value of $\sigma$. (The large natural variability of sea surface density at low 
latitudes due, in part, to river inflow adds noise to the calculation, but also note that density coordinates give excessive resolution to the warm water of the ocean compared to the cold water. As a percentage of the total range, density varies by roughly $75 \%$ just over the water warmer than $20^{\circ} \mathrm{C}$, leaving only $25 \%$ of the range to colder water.) Based on Hastenrath's (1980) maps of tropical ocean heat gain, Csanady (1984) emphasizes that the bulk of the warm water formed is water that has upwelled along the equator. Schmitt et al.'s (1989) density flux maps suggest that low-latitude coastal upwelling also may contribute significantly to the supply of warm water.

As a result of the heating at one end and strong cooling at the other, water is leaving the intermediate density range ( 22.5 to 26 , where $M<0$ ) at a rate given by the difference, or about $38 \times 10^{6} \mathrm{~m}^{3} \mathrm{~s}^{-1}$. This amount must be replenished if the total volume of intermediate density water is to remain constant from year to year. Two sources exist to balance this loss. The first of these is cross-isopycnal mixing, which may occur either near the surface or in the interior. The second is flow at the boundary of the North Atlantic Ocean, including that to and from marginal seas and across the equator. Marginal seas supply water typically at high density, but cross-equatorial flow certainly exists at a variety of densities. For example, northward flow at the western boundary on the equator extends from near surface in the North Brazil Coastal Current to deeper levels in the Antarctic Intermediate Water. Near the equator only shallow water warmer than about $20^{\circ} \mathrm{C}$ lies within the intermediate density range though, and no plausible transport of the North Brazil Coastal Current could account for all the necessary mass. Thus, mixing between very warm shallow water and surrounding cooler water appears to have a dominant role in the production of water of intermediate density. Unfortunately, we cannot say from our calculation where the mixing mainly occurs.

Niiler and Stevenson (1982) extended a heat budget calculation south of the equator over the region enclosed by the $25^{\circ} \mathrm{C}$ isotherm ( $\sigma$ approximately 24 ), thereby canceling out the effect of cross-equatorial flow (or any other mean flow). They concluded that interior mixing was responsible for removing the heat supplied at the surface. Here we see the mixing necessary to balance mass over a wide range of densities, which may be useful to compare to measurements of mixing on different isopycnal surfaces.

A familiar result from studies of heat transport in the North Atlantic is the location of a maximum northward transport near $30^{\circ} \mathrm{N}$. The northward heat transport decreases south of this latitude over regions of net heat gain. This maximum has its analogue in density transport as a function of density at $\sigma=23.25$. At this density $F=0$ and $\int^{\circ} F\left(\rho^{\prime}\right) d \rho^{\prime}$ attains its maximum value as it includes the entire range of density gain. The condition that $F=0$ means that the volume transport across this isopycnal owing to air-sea fluxes alone is zero on average, illustrating the role of mixing in the transfer of heat and salt across this isopycnal, as distinct from mass. The large surface area occupied by densities close to 23.25 (Fig. 2) seems consistent with a strong horizontal mixing of heat and salt in the upper ocean, which might seem likely to homogenize properties over a broad area.

Integrating $F(\rho)$ over all densities gives the total effect of the density flux on the North Atlantic ( to $65^{\circ} \mathrm{N}$ ), which amounts to $6.1 \times 10^{7} \mathrm{~kg} \mathrm{~s}^{-1}$. Over one year the equivalent sea level decrease, obtained by multiplying the specific volume change by the average ocean depth, is about $4 \mathrm{~cm}$. The total density flux divided by the total density range gives the average transformation, or the average flow of water toward higher density. This was called the poleward drift by Walin (1982) and amounts to about $7.6 \times 10^{6} \mathrm{~m}^{3} \mathrm{~s}^{-1}$. To this figure the formation rate in the Norwegian Sea should be added, and a crude calculation of this using Bunker data alone raises the total North Atlantic sinking rate to $9 \times 10^{6} \mathrm{~m}^{3} \mathrm{~s}^{-1}$. We may compare this figure for the net sinking to the maximum transformation of 32.2 $\times 10^{6} \mathrm{~m}^{3} \mathrm{~s}^{-1}$ at $\sigma=26.1$. The latter reflects the strong subtropical gyre to subpolar gyre transfer, while the net sinking represents the strength of the thermohaline connection between the North Atlantic and the rest of the World Ocean across the equator.

The thermal and haline contributions to $F$ may be computed separately by setting $\alpha$ or $\beta$ to zero (Fig. 3 ). Evaporation dominates precipitation over most of the density range; the slight excess precipitation in the subpolar gyre shows up only at high density. Cooling dominates heating over the upper half, reinforcing the evaporation down to $\sigma=24$. At about 23.2, heating

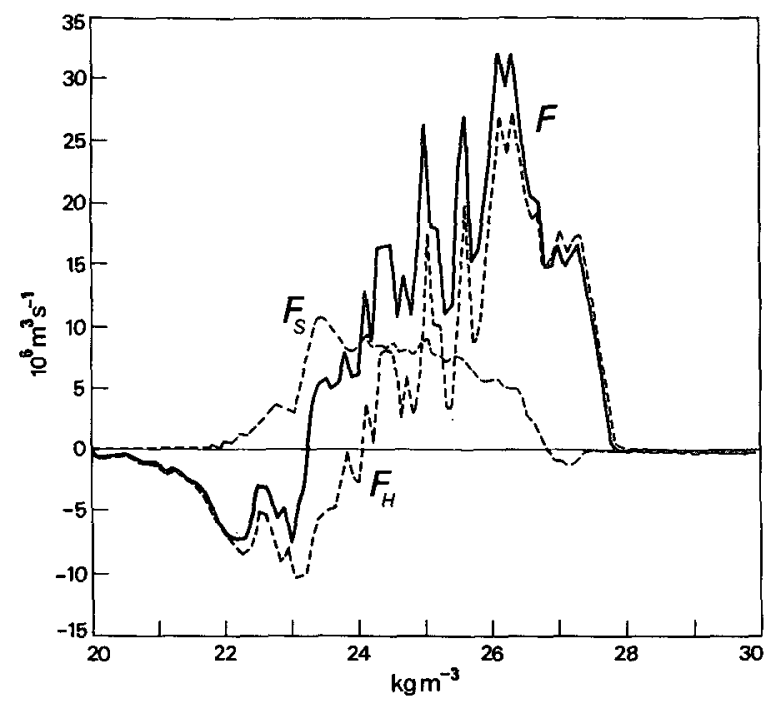

FIG. 3. Transformation (as in Fig. 1, Isemer and Hasse dataset) split into separate thermal and haline fluxes. 
finally wins out over evaporation and water is made less dense. The evaporation peak near 23.5 is notable, and it tends to form denser, saltier water over the density range associated with the surface salinity maximum (centered at about $25^{\circ} \mathrm{N}$, Worthington 1976).

Subsurface salinity-maximum water, however, is not formed by air-sea fluxes in the strict sense defined earlier: positive $M$. On the contrary $M$ is negative and air-sea fluxes tend to remove water from the density range 23-26. However, this is the density range of strong downward Ekman pumping, which drives the salty surface water into the interior along isopycnals to create a subsurface maximum. The magnitude of the Ekman pumping over this range is about $17 \times 10^{6}$ $\mathrm{m}^{3} \mathrm{~s}^{-1}$, but Ekman pumping does not transfer water across isopycnals and so does not replenish the mass lost through air-sea fluxes. It redirects the cross-isopycnal flow driven by the air-sea fluxes. Thus, a layer of the ocean is given the characteristics traditionally called "salinity-maximum water," but it does not become a volumetric mode of restricted $T-S$ values.

In the next sections the transformation curve is examined in more detail. Then seasonal cycles are discussed and the temperature and salinity of the transformation are considered.

\section{b. Subtropical mode water}

The observation of mode water in the Atlantic has a long history (Worthington 1976). This water is outstanding for its volume, perseverence, and uniformity of properties near $18^{\circ} \mathrm{C}$ and $36.5 \mathrm{psu}$ (Worthington 1976; Warren 1972). Small but significant changes over time have been documented (Talley and Raymer 1982), but these serve more to emphasize the continuity of the water mass as a whole rather than its variability. Its distinct characteristics mean that the stratification of the water column is weak within it and measures of the stratification such as stability or the large-scale potential vorticity have therefore been used to map its distribution (McCartney 1982). The weak stratification points to its origin in convection forced by strong cooling of the sea surface during winter.

McCartney's (1982) description of mode water shows clearly its presence centered near $17.5^{\circ} \mathrm{C}$ and $\sigma$ $=26.5 \pm 0.1$ on $50^{\circ} \mathrm{W}$ in the North Atlantic. This density is in the middle of the formation range calculated here between 26 and 27 (Fig. 2). Within this range, close to $14 \times 10^{6} \mathrm{~m}^{3} \mathrm{~s}^{-1}$ are formed. If all of this water were to become mode water, it would represent a net supply of $4.4 \times 10^{14} \mathrm{~m}^{3}$ for the year. Using Worthington's (1976) value for the volume of water between $17^{\circ}$ and $19^{\circ} \mathrm{C}, 1672 \times 10^{3} \mathrm{~km}^{3}$, a supply of $440 \times 10^{3} \mathrm{~km}^{3}$ renews $26 \%$ each year. We will see later that the maximum calculated formation occurs not only at the right density, but the correct temperature and salinity as well.
Warren (1972) identified the seat of subtropical mode water formation at $35^{\circ} \mathrm{N}, 60^{\circ} \mathrm{W}$ and also inferred that formation should occur in a band roughly between $30^{\circ} \mathrm{N}$ and the Gulf Stream based on calculated winter minimum temperatures and on mixed-layer depths over a somewhat broader latitudinal range. Furthermore, he showed that the southward extension of the mode water underneath a secondary seasonal thermocline might follow from the extension of the onedimensional model to include a southward component of mean flow. Woods and Barkmann (1986) simulated mixed-layer convection over a wide area of the North Atlantic using a sequence of one-dimensional models translating with a specified velocity. Based on the annual excursion of mixed-layer depth, they estimated a subtropical mode water formation rate of $446 \times 10^{3}$ $\mathrm{km}^{3}$ and located the formation in a strip following the curve of zero net annual density flux (roughly on a line between Bermuda and the Iberian Peninsula). The closeness of their estimate to ours gives support to their model, and in return, the mixed-layer modeling provides a complementary picture by showing how the convection process is spatially distributed.

To see how our estimate depends on the density bin width $\Delta \rho$, a number of calculations were done using other widths (Table 1). The value of $F$ at $\sigma=26.2$ and $\sigma=27$ are presented, and their difference $\Delta F$ is $13.71 \times 10^{6} \mathrm{~m}^{3} \mathrm{~s}^{-1}$ with a standard deviation of 1.03 $\times 10^{6} \mathrm{~m}^{3} \mathrm{~s}^{-1}$. The range of $\Delta \rho$ shown spans the practical limits of the data. One could not decrease $\Delta \sigma$ much below 0.05 before the physical separation of the density band would be less than the $1^{\circ}$ square resolution of the data. Increasing $\Delta \sigma$ beyond 0.1 to 0.5 spreads out the strongest air-sea fluxes over too broad an area. The average of $F$ over all density is unchanged by different bin widths, as it should be. Thus, aside from questions about the limited resolution of the data, but recognizing that the original Bunker heat flux data give almost the same result, we consider the estimate accurate to about $20 \%$. Worthington (1976) reiterated his earlier renewal estimate of $26 \%$ per year, but was so uncertain about it that he did not include it in his box model of the warm water layer in the North Atlantic.

\section{c. Subpolar mode water}

McCartney and Talley (1982) charted in detail the evolution of another mode water around the subpolar

TABLE 1. Transformation at two densities for several choices of density bin width $\Delta \sigma$.

\begin{tabular}{lccc}
\hline \hline$\Delta \sigma$ & $\sigma=26.2$ & $\sigma=27$ & $\Delta F$ \\
\hline 0.05 & 29.02 & 16.22 & 12.8 \\
0.1 & 29.25 & 16.66 & 12.6 \\
0.15 & 30.30 & 15.26 & 15.04 \\
0.2 & 30.44 & 15.61 & 14.83 \\
0.5 & 24.84 & 15.40 & 9.44 \\
\hline
\end{tabular}


gyre, from a density of about 27 east of the North Atlantic Current up to the density of Labrador Sea Water near 27.8. On the transformation curve (Fig. 3), water mass formation begins at $\sigma=27.3$ and continues up to the highest densities found. The total formation in this range $F(27.3)$ is $16.7 \times 10^{6} \mathrm{~m}^{3} \mathrm{~s}^{-1}$.

As is clear from McCartney and Talley's (1982) observations, though, this "mode" is spread out over a wider range of density than subtropical mode water, so it does not seem useful to speak of an overall renewal. High volume Labrador Sea Water and other water masses at densities greater than 27.5 receive the majority of the water $10.5 \times 10^{6} \mathrm{~m}^{3} \mathrm{~s}^{-1}$, but the percentage renewal is reduced because the volume is large. Density classes between 27 and 27.4 receive less mass on average but volumes are also smaller. A residence time scale in any density class may in principle be estimated by dividing the volume by the formation rate, but characteristics in any given class may be renewed to some extent even if the net annual formation is zero, since this only means that the amount of water entering due to air-sea fluxes equals the amount leaving during the year, that is, no net mass supply ( see seasonal cycles below).

The amount of water supplied to the subpolar gyre estimated here is within $20 \%$ of McCartney and Talley's (1984) box-model result for the whole system (14.1 $\times 10^{6} \mathrm{~m}^{3} \mathrm{~s}^{-1}$ ). Although they used Bunker's data, the net heat loss, at least, is pretty much the same as in Isemer and Hasse's revision.

\section{d. Formation}

The distribution over density of formation is shown by $M$ (Fig. 4). Derivatives naturally increase noise, and to reduce this the bin width was doubled to $\sigma=0.2$. For comparison the Ekman pumping contribution $M_{E}$ is shown. This is obtained by integrating the Ekman pumping over the surface area of each density bin, similar to the calculation of $F$. It shows how much water leaves the Ekman layer and enters the interior (or vice versa) as a function of density during one year.

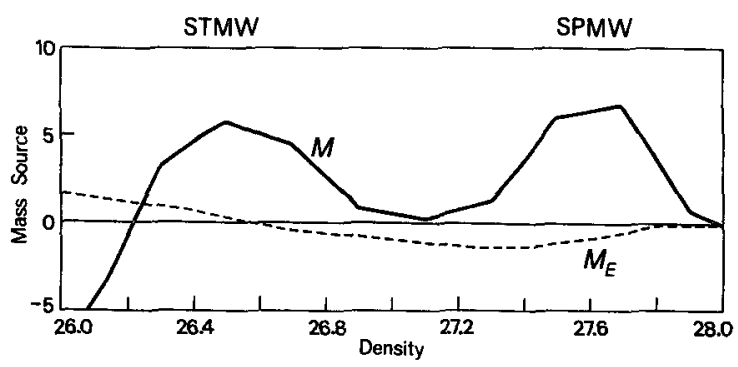

FIG. 4. Mass source $\left(\times 10^{6} \mathrm{~m}^{3} \mathrm{~s}^{-1}\right)$ from density flux $(M)$ and Ekman pumping $\left(M_{E}\right)$ in the upper part of the sea surface density range. The left-hand lobe is centered near the density of subtropical mode water (STMW) while the right-hand lobe spans subpolar mode water (SPMW) and Labrador Sea Water densities.

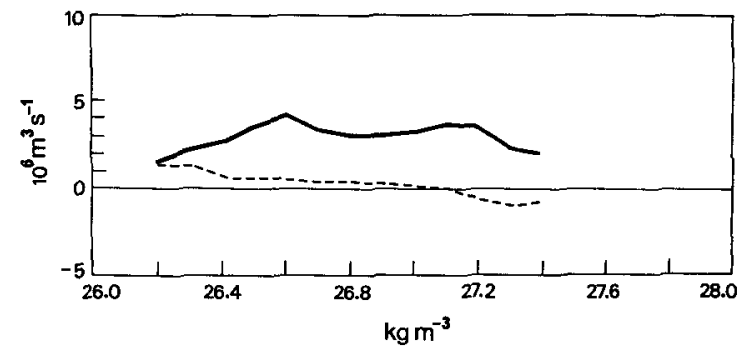

FIG. 5. Adapted from Sarmiento (1983, his Fig. 4b) showing his calculation of exchange between the surface layer and interior from tritium measurements (solid) and an estimate of Ekman pumping (dashed).

The two peaks in $M$ are associated with the production of the two main mode waters discussed in section 1 . The first maximum is at 26.5 , the density of subtropical mode water. The second maximum is at 27.7 , somewhat less dense than Labrador Sea Water. This formation ought to supply well-oxygenated water to the interior, and indeed the minimum at 27.1 is satisfyingly close to the density of the average oxygen minimum at 27.2 (Richards and Redfield 1955).

The mass source and sink from Ekman flow is weaker throughout the density range shown. At intermediate densities it becomes comparable in strength to the formation by air-sea fluxes (not shown). Probably the most interesting result at these higher densities is the zero Ekman source at about 26.6, close to the average density of subtropical mode water. Thus, Ekman pumping plays essentially no direct role in the mass balance of the subtropical mode water.

It is instructive to compare the formation $M(\rho)$ to Sarmiento's (1983) calculation of a related quantity he called exchange or replacement rate of old interior water with new surface mixed-layer water (Fig. 5). The figures resemble one another, but the differences are important. A single example illustrates why. The tracer data shows a substantial replacement rate at $\sigma=27$, whereas the air-sea flux data show essentially no mass source at this density. Sarmiento did note that tracer properties may be completely renewed by convection, while volumetrically the mixed-layer renewal may be incomplete. Thus, tritium may be entering by long- or cross-isopycnal mixing from the surface even when there is no net supply of water from the surface to the interior on this isopycnal.

\section{e. Seasonal cycles}

To improve our understanding of the averaged annual water mass formation rates it is worthwhile to consider examples of their seasonal variation. A complete description of seasonal effects is not given here, but a few remarks are useful at this point to complement the previous sections. 
The division of the formation rate into two primary lobes suggests that the overall conversions might be ascertained from the progression of $F$ at the two values 26 and 27 through the year. Fortunately, these show a fairly simple behavior, with essentially all $15 \times 10^{6}$ $\mathrm{m}^{3} \mathrm{~s}^{-1}$ of annual production in this density range occurring during the month of January (Fig. 6). In fact, most of subtropical mode water formation occurs later in winter. By January, however, the warm water of the seasonal thermocline has been converted to denser water and is available for further conversion in the following months into the observed mode water. This is shown by the maximum $F$ at 26.4 in March of $10 \times 10^{6}$ $\mathrm{m}^{3} \mathrm{~s}^{-1}$, while $F(26)$ and $F(27)$ are both smaller and almost equal at this time. The $15 \times 10^{6} \mathrm{~m}^{3} \mathrm{~s}^{-1}$ of subpolar mode water production is obtained from a gradual buildup of $30 \times 10^{6} \mathrm{~m}^{3} \mathrm{~s}^{-1}$ over approximately half of the year from October to March, followed by the removal of half that amount.
The Ekman source $M_{E}$ seems to lag the transformation by 1-3 months, depending on which peaks one chooses to measure (Fig. 6a), since mixed-layer density takes some time to respond to the surface density flux (Warren 1972). The pumping, made possible in winter by the excursion of some isopycnals to lower latitudes where the Ekman transport converges and water downwells, is canceled in summer by their return to the subpolar gyre, where water upwells. Another illustration of this migration is the average density of the border between the two gyres or the zero Ekman source density as a function of month (Fig. 6a, bottom). This is as high as 27 in April and as low as 25.8 in August. Thus, in late summer almost the entire thermocline is subject to drainage by Ekman suction, helping to lower the average zero source density to values as low as those of subtropical mode water.

The transformation $F$ basically divides into a "fall plus winter" density gain period and a "spring plus
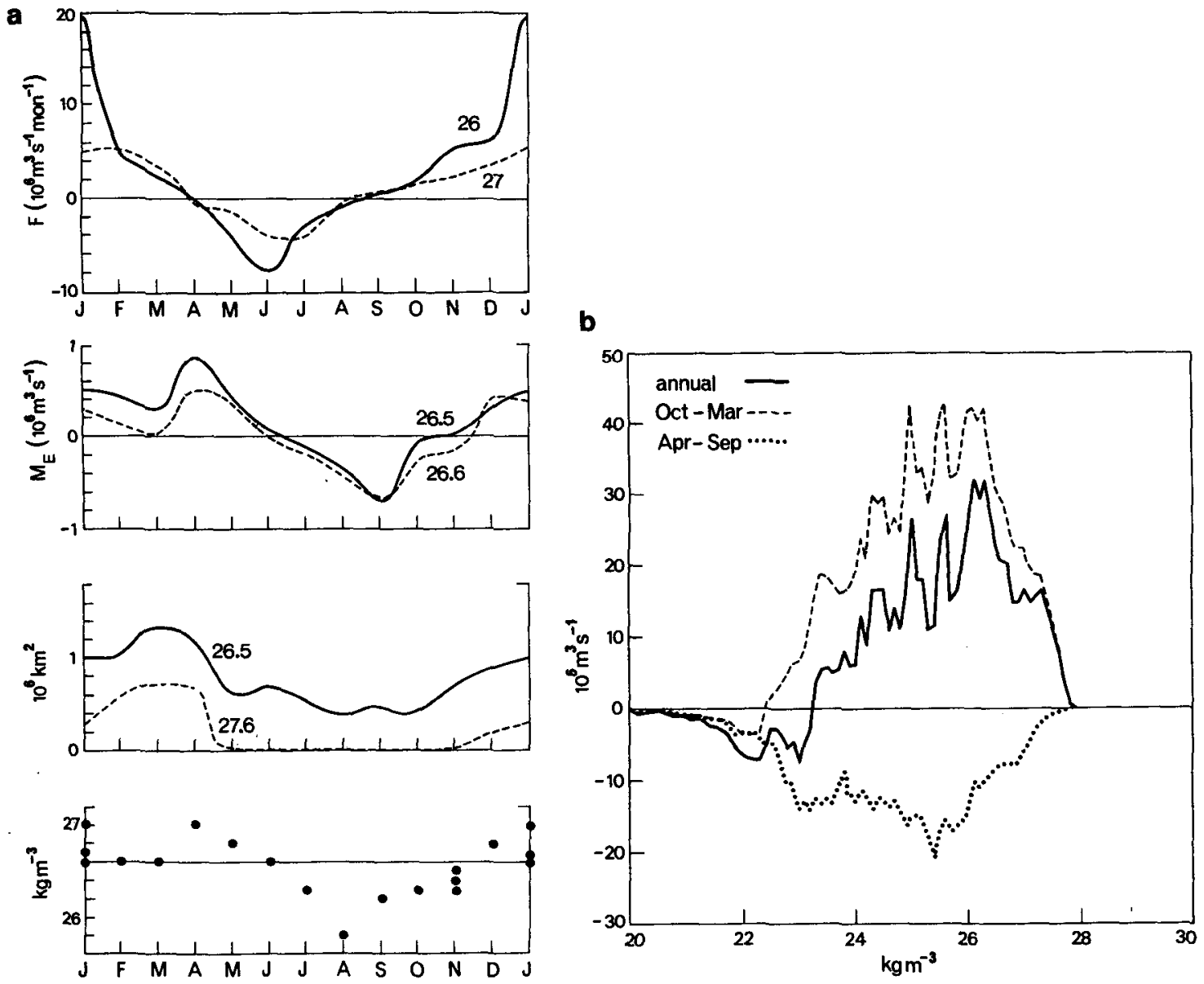

FIG. 6. (a) Seasonal cycles of several variables. From the top: transformation at selected densities, Ekman pumping at selected densities, outcrop area, and the average density of the border between gyres (density of zero net pumping). (b) Transformation divided into the fall plus winter component and the spring plus summer component, showing the basic division of the year into a "heating" season and "cooling" season. (For easier comparison the transport values are all averaged over one year, artificially reducing the seasonal values by a factor of two.) 
summer" density loss period (Fig. 6b). During the summer months water leaves the interval $\sigma>26$ at a rate of about $20 \times 10^{6} \mathrm{~m}^{3} \mathrm{~s}^{-1}$. Most of this water is deposited to the density ranges 24-25 (subtropics) and 22-23 (tropics). In winter the transformation reverses and doubles in strength.

\section{f. Formation in the $S-T$ plane}

Water of widely varying temperature and salinity can have a density within the range of either subtropical or subpolar mode water. Yet it is the special values of these quantities that are the most familiar signs and the more fundamental definition of water types. The water mass formation curve as a function of $\rho$ cannot show this. To do so, temperature and salinity bins of width $0.5^{\circ} \mathrm{C}$ and $0.1 \%$ were defined, and a histogram of $F(S, T)$ was constructed over the $S-T$ range 30-38 psu and $3^{\circ}-38^{\circ} \mathrm{C}$ (Fig. 7). The result shows the transformation over a broad area of the $S-T$ plane, with a maximum at roughly $20^{\circ} \mathrm{C}$ and 36.5 and another one near $8^{\circ} \mathrm{C}$ and 35 psu. Relatively large negative densification is confined to the warmest band above $20^{\circ} \mathrm{C}$. Irregular peaks, both positive and negative occur in the cool, fresh sector of the plane, mostly representing transformations near the coast at higher latitudes.

To see the relation to the transformation curve, note that $F(\rho)$ can be recovered by integrating along the path $\rho=$ const:

$$
F(\rho)=\int_{-\infty}^{\infty} F(S, T) d \chi,
$$

where $\chi$ is a parameter along the path. The value of the decomposition of $F(\rho)$ into $F(S, T)$ lies in the demonstration that the form of $F(\rho)$ is not the result of a random constructive contribution from different $T-S$ values, but reflects the net effect of transformations among well-defined water types. The maximum in $F(\rho)$ near $\sigma=26$ appears as a warm maximum in $F(S, T)$, while the plateau in $F(\rho)$ near $\sigma=27$ appear as a separate, distinct, and cooler ridge in transformation on the $S-T$ plane. This shows how the subpolar mode water source has a wide range of temperatures and salinities compared to the subtropical mode water source.

To define the mass source or water mass formation as a function of $S$ and $T$, form the gradient of $F(S$, $T$ ) orthogonal to isopycnals:

$$
M(S, T)=\frac{-\nabla F(S, T) \cdot \nabla \rho(S, T)}{|\nabla \rho|}
$$

or

$$
M=\left[\frac{T_{0}^{2} \alpha(\partial F / \partial T)-S_{0}^{2} \beta(\partial F / \partial S)}{\left(T_{0}^{2} \alpha^{2}+S_{0}^{2} \beta^{2}\right)^{1 / 2}}\right],
$$

where

$$
\nabla=\left(S_{0} \frac{\partial}{\partial S} T_{0} \frac{\partial}{\partial T}\right)
$$

A late winter example was chosen to illustrate the relevance of $M(S, T)$ to subtropical mode water formation (Fig. 8). A simple Laplacian smoothing in the $S-T$ plane has been done to reduce noise, which is more or less equivalent to the earlier bin width increase to 0.2 made to form $M(\rho)$, and the scales $S_{0}=1 \%$, $T_{0}=1^{\circ}$ were chosen. For this example, the peak formation occurs at $17.5^{\circ} \mathrm{C}$ and $36.5 \mathrm{psu}$, both of which correspond to the traditional characterization of subtropical mode water within the resolution of our cal-

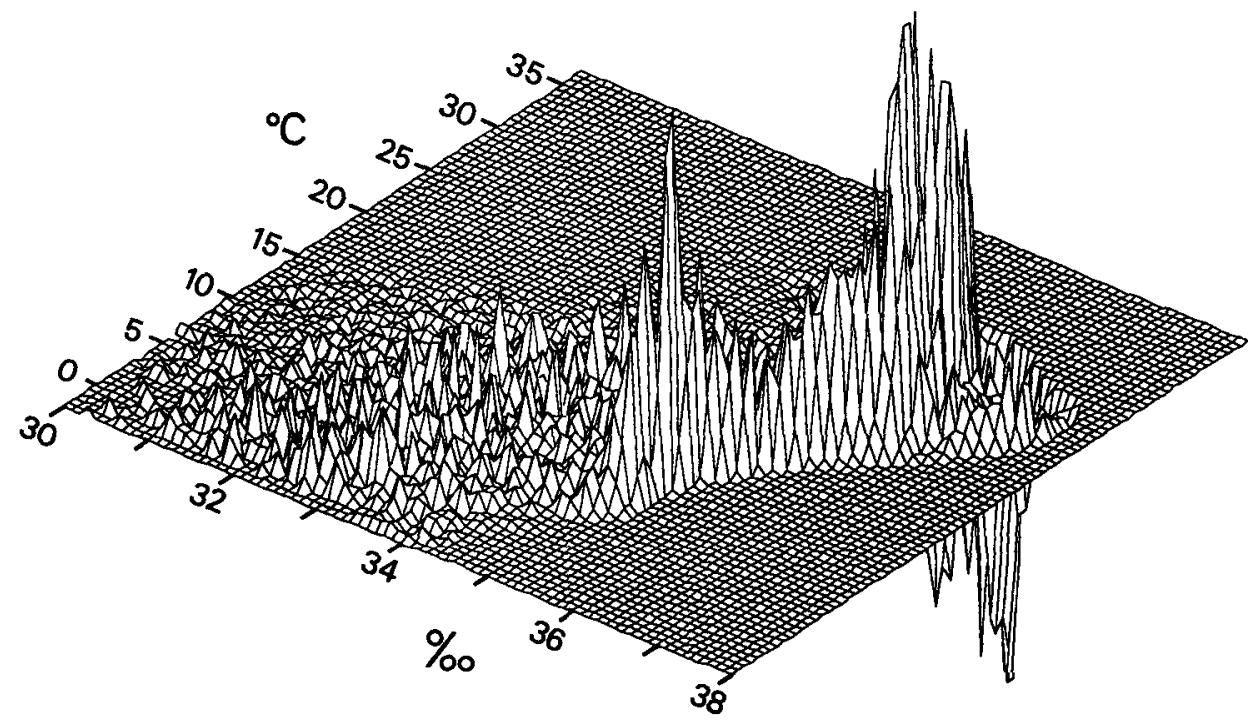

FiG. 7. Annual average transformation $F(S, T)$ in the $S-T$ plane. 


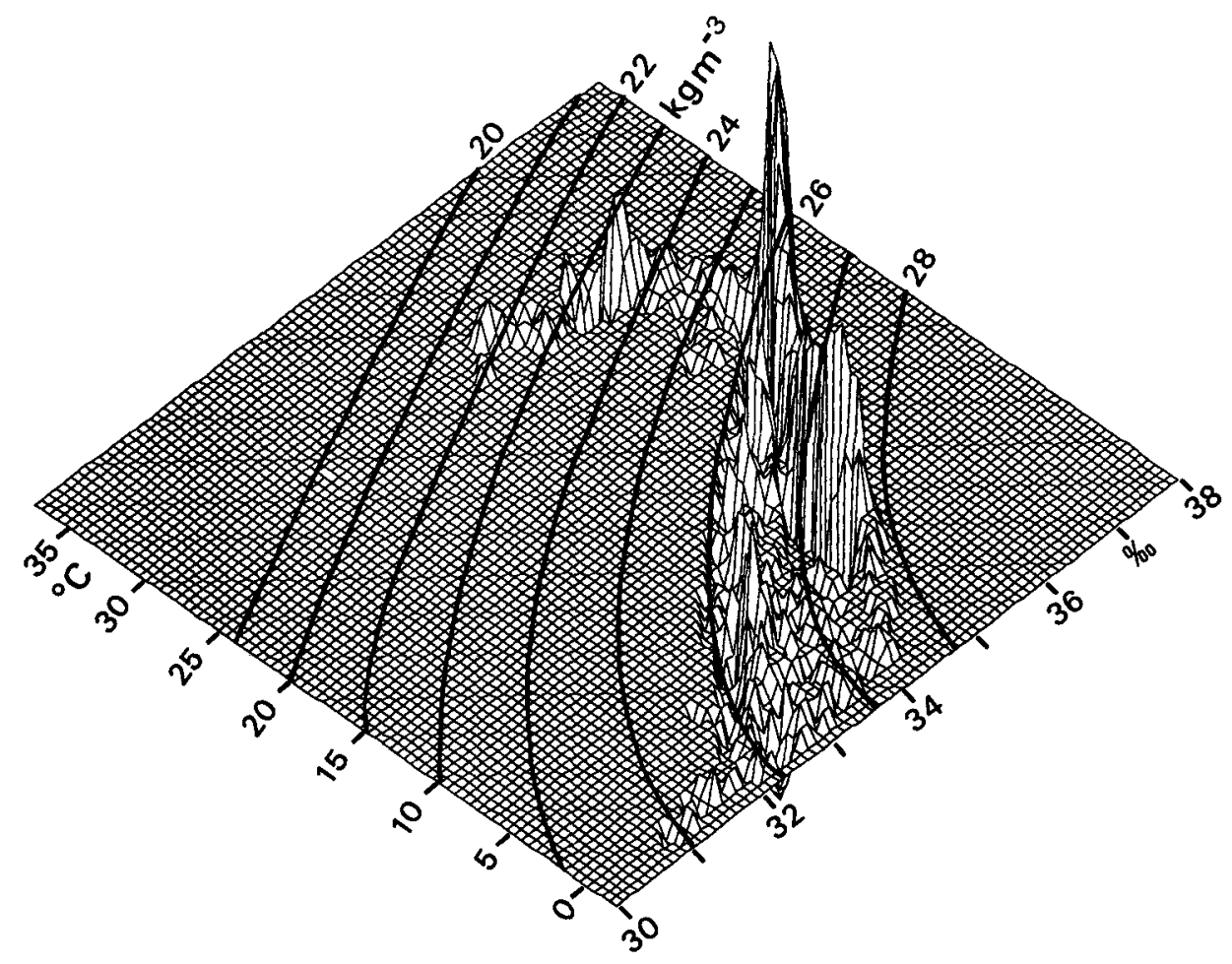

FIG. 8. March formation in the $S-T$ plane. Density isopleths are superimposed.

culation. This is moreover the coldest and densest maximum of the year (Table 2). The arbitrariness of the scaling renders the formation values themselves meaningless and we are unable to compare them to the transformation $F(\rho)$. However, they do indicate the relative amount of water formed in each $T-S$ class, and the fact remains that more water near $18^{\circ}$ is replenished each year than any other.

Other peaks come and go from month to month, and may be important in certain regions. For instance, the formation peak in the vicinity of $27^{\circ} \mathrm{C}$ and $36 \mathrm{psu}$ might be related somehow to the volume maxima near that temperature and salinity (Wright and Worthington

TABLE 2. The maximum formation rate for each month (arbitrary units) and the values of $T, S$, and density at the maximum.

\begin{tabular}{ccccc}
\hline \hline Month & $T\left({ }^{\circ} \mathrm{C}\right)$ & $S(\mathrm{psu})$ & $M$ & $\sigma$ \\
\hline 1 & 19.5 & 36.6 & 0.87 & 26.12 \\
2 & 18.5 & 36.6 & 0.52 & 26.37 \\
3 & 17.5 & 36.5 & 0.19 & 26.55 \\
4 & 20.0 & 36.5 & 0.11 & 25.91 \\
5 & 18.5 & 36.2 & 0.28 & 26.07 \\
6 & 22.5 & 36.4 & 0.32 & 25.14 \\
7 & 26.0 & 36.4 & 0.29 & 24.09 \\
8 & 28.5 & 36.3 & 0.25 & 23.21 \\
9 & 28.5 & 36.2 & 0.15 & 23.13 \\
10 & 25.0 & 36.6 & 0.22 & 24.55 \\
11 & 23.0 & 36.6 & 0.60 & 25.15 \\
12 & 21.0 & 36.6 & 0.81 & 25.71 \\
\hline
\end{tabular}

1970), but it seems to be canceled out at other times during the year and does not show up in the annual mean (Fig. 1).

Any sea surface variable sorted by its associated temperature and salinity will have the general form of the interior temperature-salinity curve, at least roughly, since the characteristics created at the surface are imprinted to a certain extent onto the interior. So the fact that the formation looks like such a curve is not surprising, but it does more than this by documenting the air-sea density flux component of the process leading to the creation of this curve in the first place. For example, Iselin (1939) noted the failure of lateral turbulence to transfer the characteristics of the slope water across the Gulf Stream along isopycnals and to modify the general central water temperature-salinity relationship. The failure may be related to the lack of formation: one slope-water type is $12^{\circ}$ and $35 \mathrm{psu}$, which is clearly off the formation ridge on the fresh side at this temperature (Fig. 8). Evidently the dynamically active spreading of water with the greatest formation rate is more successful than passive lateral mixing at setting the mean temperature-salinity relation.

Why do we not see any North Atlantic Deep Water formation near $2^{\circ} \mathrm{C}$ and 34.9 psu? To begin with, the calculation shown here does not extend to high enough latitudes to include the supposed seat of formation in the Norwegian Sea. But even if it did, as Worthington (1959) pointed out, North Atlantic Deep Water characteristics at $2^{\circ} \mathrm{C}$ and 34.9 psu do not exist at the surface 
anywhere in the North Atlantic. Instead, this water is "formed" by entrainment or mixing in the ocean's interior, in plumes that flow from sills separating the Norwegian Sea from the Atlantic. Water is thereby removed from the interior at certain densities and injected at others. Speer and Tziperman (1990) showed one possible form for the interior mass source as a function of density in such a plume.

\section{Discussion}

The annual variation of all of the physical variables is substantial, and our estimate of transformation rates depends fundamentally on this variation in two ways. First of all, water that accumulates at a certain density during some part of the year may be removed at some other time. Second, the extremes of the sea surface density field change during the year, so that the formation of the warmest and coldest water does not occur all year round. The average density of the intergyre boundary, or zero wind-stress curl, varies significantly as well, from both sea surface density changes and variations in the wind field itself; not all formation takes place when it is at its maximum value.

These results emphasize that the renewal of tracer characteristics by air-sea interaction and the generation of a mass source by air-sea interaction are not the same thing, because mixing may produce one without the other. On the other hand, that makes tracer studies complementary, and future comparisons of the two methods should give important clues about the location and strength of mixing in the ocean.

Using the ideal thermocline equations, Huang (1989) has solved for the mass sources to a range of isopycnals (25.1-27.1) representing the main part of the subtropical gyre wind-driven flow. We may compare our results to his model to investigate the dynamical consequences of formation. He specifies wintertime vertically mixed surface-layer density and depth and uses annual average Ekman pumping as the forcing. The key condition giving rise to mass sources beyond those of Ekman pumping is the north-south slope of the mixed-layer depth. Solving for the steady circulation in both the interior and the mixed layer he shows how the generally southward flow is sorted by this slope into different interior density intervals. This effect is measured by a quantity he calls "lateral induction," the southward component of geostrophic flow at the base of the mixed layer integrated over the area of a given density interval. This quantity is similar to formation because density outcrops are oriented mainly east-west, and the southward flow in the mixed layer is partly cross isopycnal. This mass source is strongest in the density range 26-26.2, too low to be subtropical mode water, but which nonetheless appears to be the source of the model version of this water mass. The total source by lateral induction is $12.7 \times 10^{6} \mathrm{~m}^{3} \mathrm{~s}^{-1}$, comparable to our winter plus fall transformation dif- ference between 25.1 and 27.1 over one year of roughly $15 \times 10^{6} \mathrm{~m}^{3} \mathrm{~s}^{-1}$. The "air-sea" heat flux required in the model because of cross-isopycnal flow in the mixed layer seems backward at first: heating in the north and cooling in the south. Recognizing that the characteristic separation between isopycnals at the surface $\left(\delta \rho / \rho_{y}\right)$ is roughly the annual displacement $(v \delta t)$, or $\delta \rho / \delta t$ $\approx v \rho_{y}$, watercolumns, therefore, spend an entire annual cycle at the surface before sinking, and a net heating is plausible over at least part of the domain. The cooling needed in the south owing to northward Ekman flux (and the heating owing to southward Ekman flux north of the zero annual density flux position) probably should be attributed to mixing, not air-sea fluxes.

Huang (1989) emphasizes the role of the meridional surface density gradient $\rho_{y}$ as the primary control over potential vorticity sources and consequent thick water masses in the model near 26.2 and 27.0. To see how, consider the advective source of potential vorticity to an isopycnal at the base of the mixed layer a $f / Z_{p}$, where $u$ is velocity, $Z$ is the depth, and $\rho$ is the density of the mixed layer. Both gradients $\rho_{y}$ and $Z_{y}$ are contained in this form. Regions where $Z_{\rho}$ is large, that is, large changes in mixed-layer depth over a given density interval correspond to sources of low potential vorticity in the model. Moreover a connection between $Z_{\rho}$ and formation is suggested by the work of Woods and Barkmann (1986), who showed how incremental changes in mixed-layer depth over part of the North Atlantic up to the maximum annual mixed-layer depth $Z$ can lead to formation estimates supported by our calculations. Formation would then be the net effect of summing these incremental changes, keeping track of the density at which they occur.

The distribution of the air-sea density flux as a function of sea surface density describes the climatological state of the ocean in a way that reveals the build-up of water masses by air-sea interaction. The coupled process of water mass formation and air-sea fluxes is complicated because the circulation is linked to sea surface temperature, which in turn exerts a strong control over the air-sea fluxes. Thus, the transformation function depends implicitly on the ocean circulation; it shows how the sea surface density, outcrop area, and air-sea fluxes combine to produce various water masses. If the annual average transformation were zero everywhere, the ocean's participation in the redistribution of energy on the globe would be minor. If the transformation did not vary, then the convection would be regular and uninterrupted by the creation of special types of seawater. Instead its structure shows that two main accumulations occur at densities corresponding to subtropical and subpolar mode waters. At intermediate densities air-sea fluxes remove water while at the lowest densities another, weaker source is created by heating. At densities lower than about $\sigma=26$, Ekman pumping becomes an important mechanism for driving properties from the sea surface to the interior. 
The calculation has illustrated formation bands lying above and below the midthermocline density near $\sigma$ $=27$. What about the thermocline itself? Two paradigms for the mechanism, which forms and maintains the thermocline, are traditionally cited. The earlier one is that the $T-S$ characteristics created at the surface by air-sea interaction and mechanical mixing are carried into the interior by convergent flow (Montgomery 1938 ) or lateral mixing (Iselin 1939), re-creating in vertical profile the characteristics of the surface outcroppings. Later on, Stommel (1958), based on the theoretical model of Stommel and Veronis (1957), proposed that water, which sinks in restricted regions of the ocean, upwells everywhere else, thereby forming a thermocline as the upper boundary layer within which the upward movement of cold water balances the downward diffusion of heat.

In the mechanism promoted by Iselin (1939), the role of cross-isopycnal mixing was downplayed; however, such mixing is essential to balance mass in each density class, since the appearance of mass sources at certain sea surface densities also requires that there be sinks, however broad or localized. If the water converted to higher density is returned back across isopycnals uniformly by interior mixing, then this upwelling, times the isopycnal area, has the same form as the transformation but represents a cross-isopycnal movement in the opposite sense. Such a generalized upwelling, of magnitude $4 \times 10^{-5} \mathrm{~cm} \mathrm{~s}^{-1}$ at $\sigma=27$ (using the basin area $41 \times 10^{6} \mathrm{~km}^{2}$ ), could "make" a thermocline in the sense of the simple vertical advection-diffusion mechanism. The temperature-salinity relation within the thermocline would still be set by the temperature and salinity at the surface, but mainly by those with the greatest formation rate.

Acknowledgments. We thank H.-J. Isemer for helpful discussion about his dataset. One reviewer asked about Huang's model, which led us also to the work of Woods and Barkmann. Another pointed out the correct density factor in the air-sea freshwater flux expression. This study has been supported by the Bundesministerium für Forschung und Technologie and the United States-Israel Binational Science Foundation.

\section{REFERENCES}

Andersson, L., B. Rudels, and G. Walin, 1982: Computation of heat flux through the ocean surface as a function of temperature. Tellus, 34, 196-198.

Budyko, M. I., 1956: Teplovoi balans zemnoi poverkhnosti. Gidrometeorologicheskoe Izdatel'stvo, St. Petersburg, $255 \mathrm{pp}$. (The Heat Balance of the Earth's Surface, translated by Nina A. Stepanova, U.S. Department of Commerce, Weather Bureau, Washington, D.C.).

Bunker, A. F., 1976: Computations of surface energy flux and annual air-sea interaction cycles of the North Atlantic Ocean. Mon. Wea. Rev., 104, 1122-1140.

Csanady, G. T., 1984: Warm water mass formation. J. Phys. Oceanogr., 14, 264-275.

Doney, S. C., and W. J. Jenkins, 1988: The effect of boundary con- ditions on tracer estimates of thermocline ventilation rates. $J$. Mar. Res., 46, 947-965.

Hastenrath, S., 1980: Heat budget of the tropical ocean and atmosphere. J. Phys. Oceanogr., 10, 159-170.

Huang, R. X., 1989: On the three-dimensional structure of the winddriven circulation in the North Atlantic. Dyn. Atmos. Oceans, 15, 117-159.

Iselin, C. O'D., 1939: The influence of vertical and lateral turbulence on the characteristics of the waters at mid-depths. Trans. Amer. Geophys. Union, 20, 414-417.

Isemer, H.-J., and L. Hasse, 1987: The Bunker Climate Atlas of the North Atlantic Ocean, Vol. 2: Air-Sea Interactions. SpringerVerlag, $218 \mathrm{pp}$.

- J. Willebrand, and L. Hasse, 1989: Fine adjustment of large scale air-sea energy flux parameterizations by direct estimates of ocean heat transport. J. Climate, 10, 1173-1184.

Levitus, S., 1982: Climatological Atlas of the World Ocean. NOAA Prof. Paper 13, National Oceanic and Atmospheric Administration, Rockville, Maryland, $173+\mathrm{xv} \mathrm{pp}$.

McCartney, M. S., 1982: The subtropical recirculation of mode waters. J. Mar. Res., 40(Suppl), 427-464.

Atlantic Ocean. J. Phys. Oceanogr., 12, 1169-1188.

$\longrightarrow$, and - 1984: Warm-to-cold water coversion in the northern North Atlantic Ocean. J. Phys. Oceanogr., 14, 922-935.

Montgomery, R. B., 1938: Circulation in the upper layers of the southern North Atlantic deduced with the use of isentropic analysis. Papers in Physical Oceanography and Meteorology, Vol. VI, No. 2, $55 \mathrm{pp}$.

Niiler, P., and J. Stevenson, 1982: The heat budget of tropical ocean warm-water pools. J. Mar. Res., 40(Suppl), 465-480.

Richards, F. A., and A. C. Redfield, 1955: Oxygen-density relationships in the western North Atlantic. Deep-Sea Res., 2, 182-189.

Sarmiento, J. L., 1983: A tritium box model of the North Atlantic thermocline. J. Phys. Oceanogr., 13, 1269-1274.

Schmitt, R. W., P. S. Bogden, and C. E. Dorman, 1989: Evaporation minus precipitation and density fluxes for the North Atlantic. J. Phys. Oceanogr., 19, 1208-1221.

Speer, K., and E. Tziperman, 1990: Convection from a source in an ocean basin. Deep-Sea Res., 37, 431-446.

Stommel, H., 1958: The abyssal circulation. Deep-Sea Res., 5, 8082.

_- and G. Veronis, 1957: Steady convective motion in a horizontal layer of fluid heated uniformly from above and cooled nonuniformly from below. Tellus, 9, 401-407.

Talley, L. D., and M. E. Raymer, 1982: Eighteen degree water variability. J. Mar. Res., 40(Supp), 757-775.

- and M. S. McCartney, 1982: Distribution and circulation of Labrador Sea Water. J. Phys. Oceanogr., 12, 1189-1205.

Tziperman, E., 1986: On the role of interior mixing and air-sea fluxes in determining the stratification and circulation of the oceans. J. Phys. Oceanogr., 16, 680-693.

- _ and K. Speer, 1991: A quantitative estimate of water mass transformation in the Mediterranean Sea. Deep-Sea Res., submitted.

Walin, G., 1982: On the relation between sea-surface heat flow and thermal circulation in the ocean. Tellus, 34, 187-195.

Warren, B. A., 1972: Insensitivity of subtropical mode water characteristics to meteorological fluctuations. Deep-Sea Res., 19, 119.

Woods, J. D., and W. Barkmann, 1986: A lagrangian mixed layer model of Atlantic $18^{\circ} \mathrm{C}$ water formation. Nature, 319, 574-576.

Worthington, L. V., 1959: The $18^{\circ}$ water in the Sargasso Sea. DeepSea Res., 5, 297-305.

- 1976: On the North Atlantic Circulation. The Johns Hopkins Oceanographic Studies, No. 6, Johns Hopkins University Press, Baltimore, $110 \mathrm{pp}$.

Wright, W. R., and L. V. Worthington, 1970: The Water Masses of the North Atlantic Ocean. A Volumetric Census of Temperature and Salinity. Serial Atlas of the Marine Environment, Folio 19, Amer. Geogr. Soc., New York, 8 pp. and 7 plates. 